1 Brady, G. W., Fein, D. B. \& Brumberger, H. Nature 264, 231-234 (1976).

Crran, J., Crick, F. H. C. \& Vand, V. Acta Puigjaner, L. 5, 581 (1952).

Crystallogr. 7, 169 (1974).

BRADY et al. ${ }^{1}$ have reported that the X-ray scattering pattern from superhelical PM2 DNA differs from that of its nonsuperhelical counterpart and interpret their results in terms of unusual tertiary conformational features of the molecule. In so doing they ignore the well documented chemical ${ }^{2,3}$ and enzymological ${ }^{4,5}$ evidence that the secondary structure of superhelical DNA is abnormal and fail to attempt any estimate of the quantitative effect that this may have on their experimental results. In addition, they have ignored the evidence from electron microscopy and light scattering which supports a branched structure for all superhelical DNA molecules with the regions of secondary structure variations situated at the end of the branches ${ }^{6,7}$. As PM2 DNA possesses between four ${ }^{2}$ and eight ${ }^{3}$ of such regions the concept of three high-order superhelices distributed over the entire molecule must be equated with there being less than one such turn per branch.

Ailsa M. Campbell

Department of Biochemistry,

University of Glasgow,

Glasgow, UK

1 Brady, G. W., Fein, D. B. \& Brumberger, H. Nature 264, 231-234 (1976).

Brack, C., Bickle, T. A. \& Yuan, R. J. molec. Biol. 96, 693-702 (1975)

Jacob, R. L., Lebowitz, J. \& Kleindschmidt, A. K. J. Virol. 13, 1176-1185 (1974).

Beard, P., Morrow, J. F. \& Berg, P. J. Virol. 12, 1303-1313 (1973).

Manjardino, J. \& James, A. W. Nature 255, 249-252 (1975).

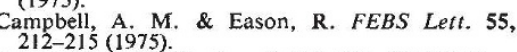

Campbell, A. M. Biochem. J. 155, 101-105 (1976).

\section{Down's syndrome in Kerala}

Kochupillai et al. ${ }^{1}$ reported an abnormally high incidence of Down's syndrome in an area of high background radiation in coastal Kerala. They stated that the radiation exposure of their study group is 1,500$3,000 \mathrm{mrad} \mathrm{yr}^{-1}$. But on the basis of a dosimetric survey ${ }^{2}$ only about $11 \%$ of the females in their study received doses in the range of $1,100-2,000 \mathrm{mrad} \mathrm{yr}^{-1}$ and $2.8 \%$ received more than 2,000 mrad $\mathrm{yr}^{-1}$. This is due to non-homogeneous distribution of monazite-containing beach sands in the region.

Kochupillai et al. observed a frequency of cases of $1: 1,076$ in the study group. Comparison with any other published value is valid if the age structures of the two populations are similar. The infant mortality in this region is about 200 per thousand births ${ }^{2}$ and is independent of the high background radiation. Furthermore, in most other surveys only $4 \%$ of all births have been to females $40 \mathrm{yr}$ old and above. The data of Kochupillai et al. show about $20 \%$ of females were in this age group, which incidentally carries the highest risk of bearing children with Down's syndrome. Although in Sweden and Germany $27-29 \%$ of the population are in the age group 0-19 $\mathrm{yr}$, in India more than $52 \%$ are in this age group ${ }^{3}$. The greater frequency of Down's syndrome in the study group of Kochupillai et al. than in those reported from other countries in ref. 1, could be explained solely in the differences in population structures.

Kochupillai et al. say: "Most striking is the higher frequency of cases of Down's syndrome born to mothers aged 30-39 yr (Table 3). This figure of $1: 81$ can be compared with $1: 880$ and $1: 290$ for maternal ages of $30-34 \mathrm{yr}$ and 35-39 yr, respectively, calculated by Penrose and Smith". But the ratio of $1: 81$ relates to the number of cases of Down's syndrome per female in the age group 30-39 yr, and the figures of Penrose and $\mathrm{Smith}^{7}$ are for frequencies among all births in these age groups. These are not comparable. Kochupillai et al. have demonstrated only that mothers in the age group 30-39 yr run a risk 10 times greater than those in the younger age group, which agrees with other evidence of increasing risk with advancing maternal age. They make no comment as to why this risk is about three times lower in mothers in the age group $40-49 \mathrm{yr}$. If high background radiation is involved, an even greater risk would be expected in this group than in comparable age groups of the general population. The age-specific risk increases almost exponentially from 1 in 290 at $35 \mathrm{yr}$ to 1 in 46 in mothers aged $45 \mathrm{yr}$ and older ${ }^{4}$.

The incidence of Down's syndrome at birth varies from $1: 520$ to $1: 873$ based on nine surveys ${ }^{4}$, with an average of $1: 663$ or 1.507 per 1,000 binths for all age groups. Frequencies at birth of around 1:800 have been reported for several population groups in India $^{5}$ which experienced normal background radiation. Lejeune ${ }^{6}$ compiled reports which demonstrated no difference between Oriental and Caucasian populations.

Based on values of family size (6.2), the number of females $(2,213)$ in the study population $(12,918)$, an infant mortality rate of 200 per thousand births and a mortality of 60 per 1,000 births in the age group $1-20 \mathrm{yr}$, a total of 11,500 births is estimated in the study population of Kochupillai et al. Using a mean value reported by Penrose and $\mathrm{Smith}^{7}$ of 1.507 per 1,000 binths, about 17 cases of Down's syndrome would be expected at birth. On the basis of data for the maternal age at birth reported by Verma ${ }^{8}$ and Collmann and Stoller ${ }^{4}$, I have made a more rigorous calculation, by redistributing the total births estimated into various age groups, on the basis of the number of females in each age group in Table 3 of ref. 1. This gives about 20 cases of Down's syndrome per 11,500 births. (The value should be even higher in this case because $20 \%$ of mothers were aged 40-49 yr, unlike any other populations studied.) This figure when corrected for mortality rate $^{7}$ would leave 9 or 10 cases in the population at the time of the study.

Kochupillai et al. observed 12 surviving cases of Down's syndrome. The differences between expected and observed are not significant. On the same basis, one would estimate three surviving cases in their control population but none were observed. The differences are not significant. Although it is difficult to explain this, it could have arisen because of the smaller sample size used for the control population as against the study group, and the possible association of a major cardiovascular defect in these cases.

\section{K. Sundaram}

Bhaba Atomic Research Centre, Trombay, Bombay 400085, India

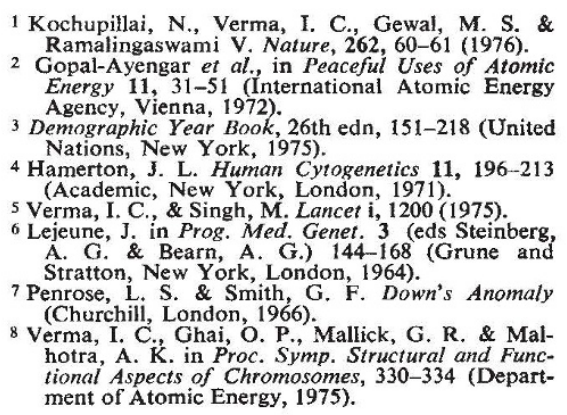

Kochupillai et al. ${ }^{1}$ reported that the prevalence of mental retardation of genetic origin was four times higher than normal in an area of high background radiation in coastal Kerala. As this background radiation is less than the limit of $5 \mathrm{rem} \mathrm{yr}^{-1}$ recommended for registered radiation workers by the International Commission on Radiological Protection in 1965, this might cause anxiety both to those exposed and to those responsible for their welfare. We therefore wish to point out two reasons why the data are hardly sufficient to imply that the likely risks are so great.

First, 'severe mental retardation' is classified as a 'genetic abnormality'. Other data make it unlikely that more than a small proportion of such cases -of which mongolism (Down's syndrome) is the commonest-are due to any simple excess, deficiency or disturbance of the hereditary material.

Second, an area selected because mongolism was known to be common 